\title{
LEADERSHIP EDUCATION: ASSESSMENT OF LEARNING IN A SPORT LEADERSHIP COURSE
}

\section{Abstract}

It is important students learn about leadership. The purpose of this study was to assess whether a leadership course for sport management graduate students led to gains in knowledge of leadership and understanding of themselves as leaders. Using quantitative (pre- and post-surveys) and qualitative (email interviews) data, this study found a one-semester course in sport leadership led to gains in theoretical and applied knowledge of leadership. Additionally, students grew personally as leaders and felt more comfortable practicing leadership in their current jobs and more prepared for future professional lives. Teachers should consider using a mix of active learning, case studies, and writing assignments to help students learn leadership concepts, practice making leadership decisions, and reflect on their leadership capabilities when educating effective leaders.

\section{Introduction}

Leadership can be defined and described in a multitude of ways. Northouse (2013) described leadership as"... a process whereby an individual influences a group of individuals to achieve a common goal" (p. 5). In addition, Kotter (1996) emphasized leadership is about dealing with the inevitability of change. Rather than conceptualizing a pyramid structure with one leader at the top, Pearce and Conger (2003) argued that increasingly leadership occurs and is shared at all organizational levels. Given these complexities and associated nuances, the importance of learning about leadership and how to lead makes pivotal differences in homes, businesses, and all facets of society and life.

What does it mean to students, however, to learn about leadership? Each student brings to class a wealth of prior experiences, which may include actual experiences as a leader, such as a working as a head lifeguard at a pool, or perceptions about leadership may emerge while observing leaders, such as a high school principal or a relative who leads a company. Past experiences, as constructivist advocates HaberCurran and Tiullapaugh (2013) emphasized, always provide students heterogenous starting points for learning. Learning about leadership also requires understanding how task accomplishment (i.e., initiating structure) and relationships among people (i.e., consideration) contribute to achieving a vision (Badshah, 2012).

Leadership education builds on students' experiences by adding theoretical, conceptual, application, and experiential knowledge through completion of assigned readings, participation in class discussions, engagement in a variety of learning activities, such 
as debates, analyses of information presented in written assignments, applications made in realworld scenarios, such as case study analyses, and exposure to practitioners' expertise through interviews. Ultimately, leadership learning occurs when students reflect continuously on experiences and knowledge gained. The overarching goals of leadership education remain-students need to learn what leadership is about, how leaders lead, and how to become a leader (Snook, Nohria, \& Khurana, 2012).

Weese and Beard (2012) posed two questions about the teaching of leadership in sport management: "What do students need to know about the area?" and "How can the topic be most effectively taught?" (p. 1). In seeking answers to these questions, they profiled three exemplary leadership courses. First, renown leadership scholar Warren Bennis co-taught The Arts and Adventure of Leadership with former University of Southern California president Steven Sample to 40 high achieving juniors and seniors majoring in any academic discipline. Students read about and examined a diversity of leaders and developed a personal leadership statement as course assignments. Second, Total Leadership, which takes a holistic approach to leadership, is taught by leadership professor Stewart Friedman in the Wharton School at the University of Pennsylvania. Friedman, who authored the highly acclaimed book Total Leadership, emphasizes five elements: student identification of personal values, promotion of lifelong learning, engagement with current leaders, integration of social media in the educational process, and experiential experiences, especially through conversations with alumni. Third, Ronald Heifetz teaches Exercising Leadership: Mobilizing Group Resources in the Kennedy Business School at Harvard University. Heifetz uses a "case-in-point" method with an emphasis on students applying theoretical knowledge to actual events, developing critical thinking skills, and getting emotionally involved with case analyses. Weese and Beard (2012) concluded from their investigation of leadership courses, "These innovative professors provide teaching and learning pedagogies and learning activities that promote deep learning, critical thinking skills, heightened student engagement, and life-cycle learning and engagement" (p. 6). Have these acclaimed teachers, however, identified the "holy grail" of content aspiring leaders in sport management need to learn?

The potential best practices highlighted in three courses by Weese and Beard (2012) accentuated learning from experts, identifying personal values, being lifelong learners, developing critical thinking skills, and learning through experience in educating future leaders. Alternatively, millions of books on leadership espouse specific leadership theories, unique characteristics of leadership, or innovative approaches to leadership the authors believe are the optimal pathways to success as a leader, or at least conduits to expanded consulting opportunities. Leadership courses abound across disciplines in higher education, but none are recognized as the course ensuring development of outstanding leaders. The content to be taught (i.e., course design) and how content is taught (i.e., instructional delivery) are essential characteristics about the teaching, which remain the purview of the professor. The unanswered questions often remaining include what content are students actually learning and are they achieving laudable student learning outcomes through effective teaching?

The professor of one required sport leadership course within a master's degree program wondered if content taught and student discussions and activities were ensuring students learned what they needed to learn. Even though students' endof-course evaluations were high and their openended comments positive, substantive evidence of advances in learning was limited. Gaining greater 
perspectives from students about what they learned and how learning potentially could benefit them in their careers led our research project. The purpose of this study was to assess whether a leadership course for graduate students in a master's degree program in sport management led to gains in knowledge of leadership and understanding of themselves as leaders.

\section{Review of the Literature}

Burns (1978) argued, "Leadership is one of the most observed and least understood phenomena on earth" (p. 2). Not surprisingly, students enrolled in college leadership courses have pre-existing beliefs (Caza \& Rosch, 2013) about who they think leaders are and what leaders do. For example, personal experiences shape beliefs about leadership (Caza \& Rosch, 2013), while existing understanding about leadership influences definitions of leadership and student motivation for participating in leadership programs (Haber, 2012). Students view leadership differently, with some having a more traditional, hierarchical, and leader-centric understanding (Haber, 2012). Unlearning, which Diamond (2008) claimed is more difficult than learning new information, may be difficult for students when taking leadership courses. Students completing preassessments (McTighe \& Wiggins, 2013) revealing their knowledge and experiences about leadership could be great starting points to help faculty plan appropriate student learning outcomes and help students achieve these learning outcomes.

Curriculum Design. In tandem with battling students' preconceived notions about leadership, a paucity of theoretical and empirical research on effective leadership curriculum design exists (Allen, Miguel, \& Martin, 2014). They recommended inclusion of learning about leadership, learning how to lead, and learning why and when to lead. Allen et al.'s (2014) proposed leadership development curriculum suggested establishing clear learning goals in foundational/cognitive knowledge, skillbuilding/behavioral, and personal growth/affective to explore personal values, motivations, and passions. They advocated leadership development curricula should contain clearly articulated end states, objectives to develop leadership, and practical experiences through which students learned how to navigate real-world challenges. Allen et al's (2014) four-part model of curriculum design for leadership development included: "Know: Obtaining declarative knowledge of terms, concepts, facts, and theories. See: Identifying and recognizing the concepts in others or the environment. Plan: Integrating existing knowledge to develop a plan of action. Do: Intervening skillfully when carrying out the plan of action" (p. 30). Allen et al. (2014) challenged leadership educators to ensure students left their institutions better prepared to lead in complex and unpredictable environments.

Living in a changing, chaotic, and complex world demands the education of future leaders prepares them to adapt continuously (Allen, Stelzner, \& Wielkiewicz, 1998). Over two decades ago, Allen et al. (1998) called for a radical shift in leadership education with new emphases on individual responsibility, long-term perspective, development of employee capacities, and sustainability. They suggested practical guidelines for open leadership processes to inform leadership education programs by facilitating connections and communication, fostering individual growth, trust, and organizational learning, ongoing reflection, articulating the organization's core purpose and values, and rewarding risk-taking.

Haber-Curran and Tiullapaugh (2013) also recommended moving away from traditional conceptions and pedagogical approaches to adaptive understandings of leadership when designing leadership education. Instead of memorization and recall of information, they advocated enabling students' construction of their own knowledge. They suggested using action inquiry, which "invites students to make meaning of their experiences and shape their own learning and the learning of their classmates" (p. 95). They also endorsed problem-based learning to help students 
learn by tackling real-world problems. Buschlen and Guthrie (2014) agreed leadership was learned by doing, with understanding theory occurring through practice. They recommended case studies and written reflections as essential in educating leaders.

Instructional Delivery. The theoretical teaching of leadership, even along with a variety of pedagogical approaches, may need greater application. For transfer of learning to occur, suggested Conger (2013), leadership education must include four essential pedagogies and interventions: (1) a cognitive component comprised of lectures, case studies, and videos; (2) skill-building experiences, which should be hands-on activities for practicing specific skills; (3) feedback from peers and others; and (4) a personal growth dimension with reflection to examine personal motivations, aspirations, passions, and values. Conger (2013) believed the biggest gap in leadership education was insufficient application, so he recommended devoting at least half of class time to reflections, self-assessments, and skill development. To remove learning gaps, Conger (2013) urged leadership educators to help students harness their potential. The optimal way for students to achieve their potential is to do leadership (Posner, 2009), with experience the key.

Hartman, Allen, and Miguel (2015) sought to provide evidence-based recommendations for choosing instructional strategies and teaching methods for developing undergraduate students' leadership abilities. They used Conger's (1992) categories of personal growth, conceptual understanding, feedback, and skill building in their analysis of 25 sources of learning, such as lectures, group projects, simulations, shadowing or observations, and role playing. Respondents, who were experienced teachers or designers of undergraduate leadership courses or programs, believed service learning and student activities helped develop each of Conger's (1992) four outcomes. Lectures were not perceived as a top source of learning, except maybe as an efficient way to teach concepts and theories of leadership. Conversely, experiential sources of learning were more highly valued. In support of development of student leadership through planning and executing a fashion show, Marcketti, Arendt, and Shelley (2011) reported significant increases between the pre-survey and post-survey mean leadership scores. They concluded, “... students demonstrated significant understanding of effective leadership behaviors and learning" (p. 170) in an event management course.

Although leadership is an inherently experiential pedagogy (White \& Guthrie, 2016), it is not the experience itself that generates the most learning. Rather, it is reflection on the experience, so leadership educators should ensure students have multiple opportunities and requirements to reflect on experiences to maximize learning. White and Guthrie (2016) found students believed reflection increased self-awareness and helped them interact with others and feel more confident in their futures. Encouraging reflection in leadership education leads to meaningful learning.

Learning Assessment. Metacognition, or thinking about thinking, and reflecting on experiences enhances the learning process, stated Roberts (2008), as individuals increase awareness of personal attitudes, beliefs, and values. Questioning assumptions of experiences and behaviors broadens perspectives, stimulates self-discovery, and may assist in developing moral and ethical responsibility. Reflection can be completed individually and collaboratively in classrooms and work settings. Becoming a reflective leader, however, takes practice, benefits from guidance, and leads to ownership of the learning process. Roberts (2008) suggested using a learning journal combined with guiding questions and group dialogue and discussion as reflective activities to help students develop and assess leadership abilities. Building reflective capacity individually can yield increased self-awareness and feelings of empowerment, while reflection in groups can enhance learning about interpersonal and team effectiveness. Practicing reflection helps in learning leadership.

Completion of a capstone course in an 
undergraduate leadership minor, according to Haber-Curran and Tiullapaugh (2013), changed student understanding about leadership. They reported students broadened their understanding of leadership, including an openness to diverse perspectives and roles and emphasis on relationship building. Students also developed an increased sense of self, including understanding the challenges and affirmations of leadership styles and roles, clarifying their purpose and vocation, and integrating leadership learning and practices. Benjamin and O'Reilly (2011) suggested leadership education in Master of Business Administration programs needed to be more relevant so graduates would be better prepared for challenges faced early in their careers. Specifically, they recommended making learning problem-based, listening to what students told them were the knowledge, skills, and abilities their jobs required, and being concerned with application as well as theory.

Several themes emerge from the literature about curriculum design, instructional delivery, and learning assessment as applied to leadership education. Leadership understanding remains elusive with individuals developing alternative beliefs and preconceived notions about what is it and how it is learned. Snook, Nohria, and Khurana (2012) contended,

Upon closer scrutiny, it is clear that some of us have been largely teaching about leadership (informing our students about the nature of the phenomenon); others have been teaching how to lead (equipping students with a set of skills and capacities enabling them to lead more effectively); and still others have focused primarily on helping our students actually become leaders (assisting students to gain access to and acquire the identity of a leader). ( $p$. xiv)

Limited evidence supports what must be required in leadership curricula and how best to ensure students learn what is essential for them to know and be able to do when completing a leadership course or program. Self-assessments, active learning pedagogies, reflections, and hands-on experiences contribute to student learning. The need remains for greater understanding about students' perceptions about what leadership is and if they feel prepared to take their learning into the workplace.

Our study focused on one sport leadership course seeking answers with these research questions. First, how did completing a course in sport leadership change perceptions and understanding of leadership among master's degree students? Second, if and how did students achieve these three course learning outcomes: (1) Through research, writing, and class discussions, students will expand their understanding of leadership to guide their thinking and growth as leaders in their careers; (2) Students will examine leadership characteristics, theories, and styles and through critical thinking and reflection apply these characteristics, theories, and styles to the sport industry; and (3) Students will read and analyze scholarly articles, case studies, and books to expand knowledge and understanding of the breadth, depth, and importance of leadership and discover the broad applications of leadership to the sport industry.

\section{Method}

A mixed-methods approach using both quantitative and qualitative methods to assess whether or not students' leadership knowledge and personal leadership understanding changed as a result of a sport leadership class was used. Prior to discussing the method, the class is described to provide context and understanding for the reader.

Design for Instruction in SPMT 5320 Sport Leadership. The course, SPMT 5320 Sport Leadership, is a required course in a Master of Science in Sport Management degree. Students were asked to read 41 scholarly articles with 2-4 assigned for each class. In addition, students were asked to read four cases, which were discussed in class. 
Students were assigned seven written assignments - four article critiques, two case study analyses, and the choice of a book report or research paper-plus an oral presentation on the book report or research paper. A purpose statement, the skills to be developed, knowledge to be learned, tasks to be completed, and a grading rubric were detailed for each graded assignment. Also, students completed a comprehensive final examination with four essay questions.

Sport Leadership was designed as a studentcentered course to actively engage all students, in alignment with Barkley and Major's (2018) advocacy of interactive lecturing. The professor developed PowerPoint slides for each of the 12 topics and placed these on the learning management system prior to the start of the semester. Students were encouraged to print these slides for note-taking, view them during class via technology devices, and use them for reviewing the content. While the professor formally presented key points from slides, interactive lectures were seldom longer than 15 minutes, always interspersed with questions, and never comprised the majority of the 150-minute class meeting once a week.

Active learning strategies varied widely and were pre-planned to achieve student learning outcomes as well as adapted to students' responses and engagement with course content. With the goal of keeping students' minds actively engaged, students were asked questions and frequently invited to talk with classmates in dyads and small groups to share perspectives and formulate responses in whole-class discussions. These interactions often were associated with questions about assigned readings for the class, learning gleaned from video clips with more information about a topic or from the experience of experts, or real-world scenarios for applying information learned. The professor's interactive, conversational approach involved each of the 27 students to check their knowledge and understanding, help them create mental pictures to make connections with prior learning, and stimulate critical and creative thinking. When students were challenged to refine and support their viewpoints, a classroom climate of shared learning and positive rapport with and among students was facilitated.

Case study analyses, debates, circles of voices, buzz groups, expository writing assignments, checks for understanding, Lino, Poll Everywhere, snowballing, guided notes, and rotating stations were representative of the active learning strategies used to enrich student learning. Each topic began and ended with learning objectives, with activities chosen to help achieve each.

Participants. All 27 students in the course participated in the pre-survey, post-survey, and email interview, all of which were given as optional class assignments. The gender and racial breakdown of the sample was $59.3 \%$ male, $74.1 \%$ White, $11.1 \%$ Black or African American, 3.7\% American Indian or Alaska Native, and 3.7\% Asian. In the sample, 44.4\% identified as Spanish, Hispanic, or Latino heritage. The average age of participants was 25 , with a range of 21 to 46 years old.

Measures. The survey has three parts. First, the professor created a pre- and post-test based on class content and expected course outcomes, which included 13 multiple choice questions and 17 true or false questions. It also included one open-ended question asking students to define what it means to be an effective leader. Second, students were given the Leadership Attitudes and Beliefs Scale (Wielkiewicz, 2000). Wielkiewicz's (2000) study, which created a purified scale using a university sample, found individuals thought about leadership processes in two dimensions. The 28-item scale included 14 items representing hierarchical thinking and 14 items representing systemic thinking, which represented two ways of viewing leadership. Questions on the systemic thinking subscale related to ideas about ethics, cooperation to accomplish organizational goals, long-term thinking, and continued organizational learning as important for leadership in organizations. In this instance, success for an organization is complex and based on a number of factors. The hierarchical thinking 
subscale included questions related to organizations being structured as a hierarchy where power and control are located at the top levels of the hierarchy. Upper levels are responsible for success as well as ensuring the safety of members. All questions were asked on a five-point Likert scale from strongly disagree to strongly agree. The coefficients alpha for hierarchical and systemic thinking were .84 and .88 respectively. Third, students were asked demographic questions. Additionally, the questions for the open-ended email interviews were created by the coauthor after reviewing the course purpose and design. The professor reviewed the questions before the open-ended questionnaire was sent to students to ensure questions were directed at student learning outcomes.

Procedure. After obtaining Institutional Review Board approval, the pre-survey and post-survey questions, Leadership Attitudes and Beliefs Scale, and demographic questions were entered into Qualtrics and an anonymous survey link created. The email interview questions were typed into a Word document to be sent to participants at the end of the course. Students were presented with the optional assignment on the first day of class by the professor. Each phase of the assignment had separate point totals, so students could choose to participate in one, two, or all three phases. Then, students were asked to contact the coresearcher immediately by email if interested in participating. Students who contacted the coresearcher were sent the link to take the pre-course survey and asked to complete it prior to class the next week. The email interview questions were sent to students two weeks before the semester ended, after their final content-filled class prior to student presentations. Students were sent the post-class survey ten days prior to the end of the semester. Students were given one week to complete the final two phases. To match the pre- and post-surveys and assign points for completion, students were asked to provide their names on each survey. Once data were collected, the coresearcher removed all identifying information from the email interviews and organized it into one document to be coded by both authors. Pre- and post-surveys were matched, and all identifying information was deleted. The file was downloaded into SPSS for analysis.

Analyses. Descriptive statistics and t-tests were run in SPSS Version 24. Braun and Clarke's (2006) thematic analysis process was used to analyze the open-ended email interview responses. The process included familiarizing one's self with the data, generating initial codes, searching for themes, reviewing themes, defining and naming themes, and producing the report. With the research questions and course learning outcomes as guides, we individually identified and reviewed themes for similarities and differences. Finally, we discussed the themes and determined how they related to the research questions and created a report connecting students' comments to themes.

\section{Results}

Quantitative and qualitative data were collected to answer the research questions. Descriptive statistics for quantitative data are reported in Table 1. The highest possible score on the leadership exam was 30.

To determine if there were significant differences on the pre- and post-tests and Leadership Attitudes and Beliefs Scale from before and after the course, paired samples t-tests were run. The difference, 3.04 points, between the before class and after class scores on the leadership test was significant $(t=4.49, p<.001)$. Additionally, the scores on the systemic thinking subscale of the Leadership Attitudes and Beliefs scale were significantly different before and after the class $(-3.41, t=-3.97, p$ $=.001)$. However, scores on the hierarchical thinking subscale were not significantly different $(-0.59, \mathrm{t}=$ $0.57, \mathrm{p}=.57)$. 
Table 1.

Descriptive Statistics

Leadership Exam

Leadership Attitudes and Beliefs Scale Systemic Thinking Hierarchical Thinking

Qualitative Evidence of Student Learning. The first research question asks if and how a course in sport leadership changes perceptions and understanding of leadership among students. Responses to the open-ended questions supported that students' understanding of leadership changed as a result of the course. Students also demonstrated understanding of who effective leaders are and what they do. Statements of support are provided under each theme below.

Changes in understanding about leadership. Students directly acknowledged the class led to changes in their understanding of leadership and broadened their knowledge. For example, Participant 20 stated, "My knowledge of leadership has changed over the course of the semester in the sense that I have gained a much better understanding of what a leader is and how many different ways a person can be an effective leader." Additionally, Participant 24 explained, "My knowledge of leadership has grown immensely and I did not know how many different theories and styles there were to leadership. I also did not know that people researched and wrote books just on leadership. I honestly thought that leadership was The Great Man theory, that people were just born to be leaders and it can't be learned." Another student, Participant 23, summed up what was learned from a theoretical perspective saying, "My knowledge of leadership has also improved. Being able to differentiate

$\begin{array}{llll}\text { Mean } & \text { S.D. } & \text { Mean } & \text { S.D. } \\ 18.48 & 2.76 & 21.52 & 2.56 \\ & & & \\ 23.33 & 5.57 & 19.93 & 4.49 \\ 34.22 & 7.43 & 34.81 & 6.95\end{array}$

between different styles has become key in how I see people lead. It has also given me different perspectives on leadership and that anyone can be a leader."

Characteristics of effective leaders. Students were asked to identify the characteristics of an effective leader. Their responses included integrity, communication skills, honesty, trust, and care. Additionally, they stated leaders must be adaptable and flexible.

Who is an effective leader? Throughout the open-ended responses, students mentioned they learned who effective leaders are and described them, which demonstrated their knowledge and understanding of leadership. A leader is effective when he or she, "...know yourleader ship philosophy and your leadership style. Knowing your values and beliefs (and sharing and aligning those values with followers)..." (Participant 5). Additionally, Participant 21 stated, "Effective leadership to me means to be able to adapt to change in the industry and being able to adequately prepare and guide your team through the change. Being prepared would require leaders to envision future change and to be constantly learning in order to better prepare their team." Students also recognized the importance of empowerment. For example, Participant 19 explained, "Effective leadership is the ability to empower others while all 
working toward a common goal."

The second research question assessed if students had achieved the three student learning outcomes for the course. Comments from students supported they learned what the professor intended. Their statements are organized by learning outcome.

Learning outcome one: Through research, writing, and class discussions, students will expand their understanding of leadership to guide their thinking and growth as leaders in their careers. The previous discussion regarding changes in understanding of leadership provided supportive evidence that students met the learning outcome's first part. The learning outcome's second part related to students' personal growth as leaders. Comments made by students suggested they also grew personally as individual leaders as a result of the class. Students specified they gained understanding about what type of leader they wanted to be. For example, Participant 24 explained, "I was surprised to learn a lot about myself in terms of leadership like what kind of leader I am or what leader I strive to be when I graduate. I was not expecting to learn about myself in the process of this class." Also, Participant 6 stated, "My knowledge of leadership has gotten sounder and I can now choose what kind of a leader I want to be." Students also mentioned they felt more prepared to be leaders in their careers, stating, "I feel like I was already a good leader, but now I am equipped with so much more knowledge to lead in pretty much any situation I get thrown in to" (Participant 12), and "It has provided me with great insight on how to not only be a good leader but also how to deal with subordinates and really get to know them to be successful" (Participant 25).

Learning outcome two: Students will examine leadership characteristics, theories, and styles and through critical thinking and reflection apply these characteristics, theories, and styles to the sport industry. Students, while not asked directly about application to the sport industry, solidified they did learn how to apply information learned in the real world based on comments responding to the open-ended questions. Evidence they were able to apply theories was provided by Participant 12, who explained, "I have learned all about the different leadership styles and how each of those can be applied in my future. I can now be a more effective leader, as well as identify leaders more effectively in the future." Additionally, one student, Participant 27, focused on applying characteristics of leaders to sport suggesting, "Honestly, leaders of integrity seem to be in short supply in the sport industry, which seems more often than not to be characterized by a winner-takeall and win-at-any-costs attitude. Replacing that sort of thinking will require a new generation of leaders who are more concerned with people than winning." Succinctly, Participant 1 intimated, "I have learned about the different leadership theories and styles and how those styles and theories are applied in a real-world, sport environment."

Learning outcome three: Students will read and analyze scholarly articles, case studies, and books to expand knowledge and understanding of the breadth, depth, and importance of leadership and discover the broad applications of leadership to the sport industry. Students' understanding of the application of leadership in sport was described under learning outcome two. In open-ended comments, students said the course taught them effective leadership was important in the sport industry and business in general. They suggested, "Leadership in sport is extremely important because of the current lack there is of quality leadership within the industry. It seems like once a year there is a groundbreaking scandal with an organization. Sports are supposed to be pure and for the love of the game and the health aspects they can have on people. When lapses in leadership make sports about money or egos, it corrupts what sports are meant to be" (Participant 10), "It is important because the sport industry plays a large role in today's society. Without great leaders, we could be negatively affecting the youth 
who participate in sports or future leaders that are grown through sport. We need great leaders who are ethical and drive great visions. In a day and age when media is so readily available, it is crucial to have great leaders guiding the way" (Participant 17), and, "Leadership is of the upmost importance to be able to accomplish goals. At times teams or organizations are lost and unable to make progress and this is when leaders come into play and can turn an organization around. Their ability to make tough decisions, the ability to envision the company going somewhere in the future, and their ability to communicate effectively makes them a great asset. Leadership can be found anywhere in good teams and organizations. Leadership is not only found at the top of the organizational structures if things are done correctly" (Participant 21).

\section{Discussion}

The scholarship of teaching and learning demands educators assess and enhance their teaching to improve student learning. Thus, the action research project examined whether a sport leadership course helped students learn theoretical and applied leadership knowledge and grow personally as leaders. Past research leadership education suggests best practices for courses to improve student knowledge and personal understanding of leadership (Allen et al., 2014; Buschlen \& Guthrie, 2014; Conger, 2013; Haber-Curran \& Tiullapaugh, 2013; Hartman et al., 2015), although little research exists assessing the changes and advances in students' knowledge.

Wielkiewicz (2000) in the development of the Leadership Attitudes and Beliefs Scale identifies two dimensions-hierarchical thinking and systemic thinking. The hierarchical thinking subscale describes perceptions of upper-level leaders who exert power and control and take responsibility for organizational success. The systemic thinking subscale is more diverse and associated with individuals focused more on ethics, cooperation among individuals, long-term thinking, and the need for organizational learning. In our study, scores on the systemic thinking subscale were significantly higher on the pre-test than the post-test, and scores on the hierarchical thinking subscale did not change significantly. The first finding is surprising based on students' responses to the interview questions-with most students commenting on components of systemic thinking as essential characteristics for leaders, such as demonstrating ethical behavior, developing relationships, and establishing a vision. It might be that while students learned these behaviors were important for leadership, they still struggled to see these concepts from an organizational perspective, which is how most questions on the scale are worded, and only perceived them to be important from an individual perspective. The instructor could add more examples of organizations with a more systemic approach to help students connect to a more macro view of leadership characteristics. Expanding applications outside of the sport industry also could reinforce learning because sport management deals with the business of sport. The second finding is not entirely surprising for two reasons. First, the sport industry is hierarchical from playing fields and courts with command-and-control coaches directing teams to front offices characterized by formalized organizational structures and job responsibilities. Second, the sport industry is heavily dominated by males, like the students completing this scale. Such hierarchical thinking could, as Wielkiewicz (2000) suggested, lead to inflexibility in adapting to industry complexities and changing markets. The lack of change in pre-test to post-test scores on the hierarchical thinking subscale may suggest more entrenched attitudes along with resistance or unwillingness to adapt to changes in positional power inside and outside the sport industry.

Similar to Marcketti et al. (2011), our study's results suggest students achieved gains in understanding about leadership, including theoretical and practical improvements. Students scored significantly higher on the post-test than the pre-test indicating the course resulted in a better understanding 
of leadership theories, characteristics, and applications. Also, students explicitly stated they learned more about leadership by taking the class. From the professor's perspective, improvements provide evidence the design of the course with its readings and assignments supported student learning. Students' open-ended comments seems to suggest increased self-confidence as leaders.

One open-ended comment on the course evaluations seems particularly salient to how a course in sport leadership changed students' perceptions and understanding of leadership. A student wrote, "Really enjoyed the class and the learning structure. Enhanced my knowledge of leadership with key points that I can use toward my future career." Several students' responses to the interview questions confirmed how active learning activities like case studies, as Buschlen and Guthrie (2014) and Conger (2013) recommended, contributed to transfer of learning from theory into practice. Several students emphasized the importance of values such as integrity and honesty, which aligns with the importance of leaders' actions demonstrating values, as affirmed by Allen et al. (1998), Allen et al. (2014), Conger (2013), and Roberts (2008). The salience of values to leaders appeared to be empower students to want to embrace leadership opportunities.

As Allen et al. (1998) and Conger (1992) suggested years ago, personal growth of a leader is essential for success. We feel our most important outcomes were students' indicating they grew personally as leaders, gained a better understanding of the type of leader they wanted to be, and felt more comfortable in professional and personal leadership situations. Although students would likely have grown personally as leaders over time, and research suggests students learn by doing, at the very least this course helped them head into their professional careers with an advantage of understanding leadership and where they are at as leaders. Growing as leaders, regardless of the setting, was important to students as a result of this course.
A student on the end-of-course evaluation wrote, "(author's name redacted) helped me to find the leader inside of me. Great class, a lot of information learned." A student commented in response to the interview questions, "I would read the Authentic Leadership book. I really wanted to dig deep into what an authentic leader was. This book was a game changer for me." Other students chose as examples of effective leaders, with most outside of the sport industry, those they learned more about in the books they read, while others described learning more about leadership theories and styles that were the focus in books read or research papers written. Learning the importance of leadership traits such as developing communication skills and building relationships with followers were frequently highlighted in students' comments.

The importance of reflection in learning about leadership was emphasized by Allen et al. (1998), Buschlen and Guthrie (2014), Conger (2013), Roberts (2008), and White and Guthrie (2016). Numerous students in responding to the interview questions affirmed how the process of thinking about what they had learned in the sport leadership course changed their perceptions, deepened their understanding, and better prepared them for future leadership roles broadly defined. The overall tenor of the comments from students seemed to affirm building personal reflective capacity strengthened self-awareness, as Roberts (2008) posited.

Multiple action items for teachers resulted from our study. One suggestion is for teachers to consider using a pre-survey and post-survey, which could be a useful way to start courses for two reasons. First, teachers of leadership courses need to conduct pre-assessments to encourage students to examine their pre-conceived notions and current thinking (Tanner, 2012), which could motivate students to metacognitively recognize what they do not know and understand, thus opening their minds to greater learning. Another beneficial outcome would be for teachers to adjust content to be included or instructional approaches to be used. Second, teachers of leadership courses need to ensure they 
guide students in actually learning what is most important. For example, differentiating between the definitions of two leadership styles on an objective question survey seems much less important than learning how to situationally apply leadership skills in resolving real-world challenges in the workplace. Also, teachers could consider a post-then-pre-test design, which would allow students to reflect upon what they learned by assessing their knowledge after the course in comparison to their knowledge at the beginning of the course at one point in time. The results of this type of design can also give the teacher immediate feedback on which learning goals students made progress on, even if they did not become proficient in their leadership knowledge.

Additionally, students added a few suggestions for ways to shape future course content in a class, even in class with means on the three University's questions of $4.9,4.8$, and 4.8 (out of maximum score of 5.0). Building on learning about leadership theories and styles, a student in responding to the interview questions recommended identifying key leadership styles used specifically in sport businesses and focusing more on these, including with more assignments to take leadership roles in real-world scenarios with the task of deciding what decisions to make. Another suggestion was to have small groups of students lead discussions about assigned readings. Possibly adding even more hands-on activities could help students realize personal and others' leadership traits through reallife examples of men and women who embodied these. Expanding on examples in non-sport settings might strengthen learning, too.

Also, while not all sport management programs include a sport leadership course, program directors should consider requiring the course, especially since leadership is critical in the sport industry. As mentioned by students, scandals and ethical failures in sport necessitate strong leaders who care about development of followers and have integrity.

Finally, after reflecting on the sport leadership course, how it was taught and what students reported they learned, what they believed was most beneficial in their future careers, and what might be added to the course, two overarching themes emerged and resonated most poignantly. First, the professor believed students taking the time to reflect on course content by responding to interview questions, assuming they participated thoughtfully, yielded important insights. As Roberts (2008) and White and Guthrie (2016) emphasized, reflection must be central in leadership education. While some reflection occurred through small-group and whole-class discussions, the professor could have been more intentional by asking more higher-level questions (McTighe \& Wiggins, 2013) and facilitating more higher-level questions among students. The professor also could have added a specific reflection requirement, such as students maintaining a learning journal (Roberts, 2008). Second, the professor could have included additional realworld applications - inside and outside of the sport industry. While case study analyses occurred in class and through written assignments, even more learning activities with real-world applications could have been included. Requiring a report on an interview with a sport leader and including sport leaders as guest speakers would have exposed students to opportunities to learn from experienced practitioners.

This course seemed strongest in helping students learn what leadership is. It effectively facilitated students learning how to lead, such as demonstrating values with integrity at the pinnacle and developing and utilizing effective communication skills. While a couple of students stated in interview responses that this course helped them in becoming leaders, ideally more could have responded similarly.

It is hoped by reading a report of our action research project in a leadership education course, readers will be able to answer the "Now what?" question using these six recommendations. 
1. Read more in the literature about effective leadership education and incorporate suggestions and ideas into course revisions made by the teacher.

2. Ask students what they already know and want to learn in a leadership course through preassessments.

3. Include intentional requirements and activities requiring student reflection.

4. Expand real-world applications, such through a variety of learning activities and possibly guest speakers.

5. Conduct action research in leadership courses taught to gain greater insights into what students are and are not learning and make course adjustments as appropriate.

6. Talk with colleagues and learn with and from them about ways and strategies to strengthen leadership education for students.

\section{Limitations and Future Research}

The main limitation of the current study is the sample was drawn from one sport management classroom at one university, making the sample size small. While all students in the class participated in the study, teachers should refrain from making broad generalizations about students. Future research should examine how a similar course impacts leadership knowledge at other universities and taught by different instructors. A larger and more diverse study would add support that the assignments and design of the class are effective in teaching leadership. There was a large variation in responses, partially because of the small sample size and partially because it is difficult for students to know exactly what they do not know. This is also a limitation of the pre-then-post-test design. Additionally, students may not score significantly better on a post-test than a pre-test because of studying habits or factors unrelated to the course itself, even though they may actually know more about leadership after taking the course. A potential option for accurately assessing gains is knowledge is a post-then-pre-test design where students are asked to respond to statements about how they felt before the class and after the class at the same time. This design helps students reflect on what they do not know and could more accurately help them assess their gains in knowledge. Finally, students' attitudes toward leadership also are shaped by their work experiences. Future studies should add a measure that examines how their graduate assistantships or full-time jobs impact their leadership knowledge, skills, and beliefs.

\section{Conclusion}

Leadership education-how best to design, deliver, and assess it-is vitally important in higher education across many disciplines and society overall because graduates become future leaders. Business school and other faculties have grappled with this quandary for decades, yet no consensus exists. One significant agreement has been reached-the emphasis must be on student learning as preparatory to challenges and complexities in the workplace.

From a design standpoint, our study reemphasizes students must learn about leadership as many students lack a comprehensive knowledge and understanding about leadership, while myths and misconceptions cloud their thinking. From a delivery perspective, leadership courses often are filled with teaching students how to lead by helping them develop and practice leadership characteristics, skills, and abilities. Since assessment of leadership education provides limited evidence, it remains questionable if students are learning to become leaders in their courses, or this more likely may occur when faced with on-the-job leadership challenges, as Benjamin and O'Reilly (2011) suggested.

Maybe leadership education needs to significantly increase two curricular components identified 
through our study. First, students must be

challenged to reflect more on knowledge and

experiences to learn in meaningful and lasting ways.

Second, students need immersion into more real-

world experiences and learning opportunities to

strengthen abilities to use their learning effectively

after graduation. 


\section{References}

Allen, K. E., Stelzner, S. P., \& Wielkiewicz, R. M. (1998). The ecology of leadership: Adapting to the challenges of a changing world. The Journal of Leadership Studies, 5 (2), 62-82. doi: org/10.1177/107179199900500207

Allen, S. J., Miguel, R., \& Martin, B. A. (2014). Know, see, plan, do: A model for curriculum design in leadership development. SAM Advanced Management Journal, 72 (2), 26-38. doi: org/10.5465/ ambpp.2014.13986abstract

Badshah, S. (2012). Historical study of leadership theories. Journal of Strategic Human Resource Management, 1 (1), 49-59.

Barkley, E. F., \& Major, C. H. (2018). Interactive lecturing: A handbook for college faculty.San Francisco, CA: Jossey-Bass.

Benjamin, B., \& O'Reilly, C. (2011). Becoming a leader: Early career challenges faced by MBA graduates. Academy of Management Learning and Education, 10 (3), 452-472. doi: org/10.5465/amle.2011.0002

Braun, V., \& Clarke, V. (2006). Using thematic analysis in psychology. Qualitative Research in Psychology, 3 (2), 77-101.

Burns, J. M. (1978). Leadership. New York, NY: Harper and Row, Publishers.

Buschlen, E., \& Guthrie, K. L. (2014). Seamless leadership learning in curricular and cocurricular facets of university life: A pragmatic approach to praxis. Journal of Leadership Studies, 7 (4), 58-64. doi:org/10.1002/jls.21311

Caza, A., \& Rosch, D. M. (2013). An exploratory examination of students' pre-existing beliefs about leadership. Studies in Higher Education, 39, 1586-1598. doi: org/10.1080/03075079.2013.801434

Conger, J. (2013). Mind the gaps: What limits the impact of leadership education. Journal of Leadership Studies, 6 (4), 77-83. doi:10.1002/jls.21270

Conger, J. A. (1992). Learning to lead: The art of transforming managers into leaders. San Francisco, CA: Jossey-Bass.

Diamond, R. M. (2008). Designing and assessing courses and curricula: A practical guide. (3rd ed.). San Francisco, CA: Jossey-Bass.

Haber, P. (2012). Perceptions of leadership: An examination of college students' understandings of the concept of leadership. Journal of Leadership Education, 11 (2), 26-51.

Haber-Curran, P., \& Tiullapaugh, D. (2013). Leadership learning through student-centered and inquiryfocused approaches to teaching adaptive leadership. Journal of Leadership Education, 12 (1), 92-116.

Hartman, N. S., Allen, S. J., \& Miguel, R. F. (2015). An exploration of teaching methods used to develop leaders-Leadership educators' perceptions. Leadership and Organization Development Journal, 36 (5), 454-472. doi:10.1108/LODJ-07-2013-0097 


\section{References}

Kotter, J. (1996). Leading change. Boston, MA: Harvard Business School Press.

Marcketti, S. R., Arendt, S. W., \& Shelley, M. C. (2011). Leadership in action: Student leadership development in an event management course. Leadership and Organization Development Journal, 32 (2), 170-189. doi:10.1108/01437731111112999

McTighe, J., \& Wiggins, G. (2013). Essential questions: Opening doors to student understanding. Alexandria, VA: Association for Supervision and Curriculum Development.

Northouse. P. G. (2013). Leadership: Theory and practice (6th ed.) Thousand Oaks, CA: Sage Publications.

Pearce, C. L., \& Conger, J. A. (Eds.). (2003). Shared leadership. Reframing the hows and whys of leadership. Thousand Oaks, CA: Sage Publications.

Posner, B. Z. (2009). From inside out: Beyond teaching about leadership. Journal of Leadership Education, 8 (1), 1-10.

Roberts, C. (2008). Developing future leaders: The role of reflection in the classroom. Journal of Leadership Education, 7 (1), 116-130.

Snook, S., Nohria, N., \& Khurana, R. (2012). The handbook for teaching leadership_Knowing, doing, and being. Thousand Oaks, CA: Sage Publications.

Tanner, K. D. (2012). Promoting student motivation. CBE—Life Sciences Education, 11, 113-120.

Weese, W. J., \& Beard, S. (2012). Rethinking the teaching of leadership in sport management. Sport Management Education Journal, 6, (1) 1-7.

White, J. V., \& Guthrie, K. L. (2016). Creating a meaningful learning environment: Reflection in leadership education. Journal of Leadership Education, 15 (1), 60-75.

Wielkiewicz, R. M. (2000). The leadership attitudes and beliefs scale: An instrument for evaluating college students' thinking about leadership and organizations. Journal of College Student Development, 41 (3), 335-346. 